\title{
Por Mais Educação e Por Uma Educação Melhor
}

Recebido em 10.06.2015. Aprovado em 20.08.2015 Avaliado pelo sistema double blind review

\author{
Esther Hermes Lück \\ estherluck@id.uff.br \\ Universidade Federal Fluminense - Niterói - RJ - Brasil \\ Neide Lúcia de Oliveira Almeida \\ n!@brasilamerica.com.br \\ Universidade Federal Fluminense - Niterói - RJ - Brasil \\ Rafael Cuba Mancebo \\ rafaelcuba@id.uff.br \\ Universidade Federal Fluminense - Niterói - RJ - Brasil
}

\section{Resumo}

O curso de extensão "A Escola e a Cidade" é um curso que se dedica à discussão do tema da educação em tempo integral nas escolas brasileiras, tema este que se insere numa das metas do Plano Nacional de Educação para o decênio 2014/2023. E como responsável pela execução deste curso, o Departamento de Empreendedorismo e Gestão tem defendido, ao longo de sua atuação junto à formação continuada de professores, uma visão empreendedora da educação. Esta visão norteia-se pela integração entre a formação de professores no que diz respeito aos conteúdos acadêmicos e disciplinares e a sua formação pedagógica. Para nós, tal formação deve se desenvolver como um contínuo, marcada pela resiliência, pelo entusiasmo e pela predisposição em abraçar a atividade docente com curiosidade, energia, capacidade de renovação e de luta contra a rotina.

O presente trabalho tem 0 objetivo de apresentar a estrutura adotada pelo Departamento de Empreendedorismo e Gestão para a oferta do curso de extensão "A Escola e a Cidade - políticas públicas em Educação", expor a experiência do planejamento, execução e avaliação e sua fundamentação teóricometodológica. Tem o objetivo, igualmente, de servir de introdução à publicação de cinco Projetos de Intervenção elaborados pelos cursistas que obtiveram destaque junto às bancas avaliadoras na conclusão do curso. Tais projetos se destacaram devido às ideias inovadoras que apresentaram e/ou impactos positivos que imprimiriam em suas comunidades, demonstrando, dessa forma, a perfeita assimilação da teoria aliada à realidade prática do contexto em que suas instituições estão inseridas.

Palavras-chaves: A escola e a cidade. Educação Integral. Plano Nacional de Educação. Educação empreendedora. 


\section{Esther Hermes Lück, Neide Lúcia de Oliveira Almeida e Rafael Cuba Mancebo}

\section{Contexto}

As políticas educacionais brasileiras, estabelecidas a partir da década de 90 , alinharam-se à reforma do estado, em consonância com as grandes mudanças no contexto econômico global. Tais mudanças foram incorporadas pelos governos através da adoção de metodologias de gestão pública baseadas em critérios de eficiência e de planejamento estratégico voltados para a melhoria nos resultados dos serviços públicos. E, na educação, verificamos a disseminação de um modelo de reforma educacional calcado na avaliação educacional e voltado para a melhoria da qualidade do ensino oferecido. Isto significa que as práticas de planejamento e gestão estratégica que vinham sendo disseminadas e a incorporação do modelo de gestão por resultados que nos anos 80 estavam orientando as reformas educacionais em vários países, encontraram afinidades entre os propósitos da avaliação educacional e as exigências da nova ordem econômica, qual seja, a abertura das economias nacionais à concorrência em escala global e ao livre movimento de investimentos e tecnologia (LÜCK; PINHO, 2014).

Essas mudanças, sem dúvida, foram decisivas para que na Conferência da Unesco, em 1990, e posteriores desdobramentos que a ela se seguiram, se criasse o consenso a favor da reforma da educação. $\mathrm{Na}$ Declaração Mundial sobre Educação para Todos, com a qual os países signatários (Brasil, entre eles) se comprometeram, consta como última cláusula a seguinte declaração:

Jamais testemunharemos um outro momento tão propício à renovação do compromisso com o esforço a longo prazo para satisfação das necessidades básicas de aprendizagem de todas as crianças, jovens e adultos. Tal esforço exigirá, contudo, um muito maior e racional aporte de recursos para a educação básica e capacitação do que tem sido feito até o momento. Todavia, os benefícios advindos deste esforço começarão a ser colhidos de imediato, e crescerão um tanto a cada dia, até a solução dos grandes problemas mundiais que hoje enfrentamos. $E$ isso graças, em grande parte, à determinação e perseverança da comunidade internacional na persecução de sua meta: Educação para Todos. ${ }^{1}$

Nesse novo cenário de integração e de concorrência no plano econômico e de redemocratização no plano político, cabia aos países reformar seus sistemas educacionais para garantir a competitividade, e nesse debate, a reforma educacional fazia parte da estratégia econômica. A educação passou a ser elemento central na preparação das novas gerações para o trabalho, para a criação das competências demandadas pela nova estrutura de empregos e pelas novas atividades produtivas.

Já iniciada fortemente na década de 80 em países como Inglaterra e Estados Unidos, a avaliação externa passa a ser no Brasil também, a partir da década de 90, o instrumento de reforma educacional para a divulgação das mudanças desejadas e para o monitoramento dos avanços a serem alcançados. A quantificação dos resultados da escola ocupa a posição central no novo modelo de gestão educacional e eleva a avaliação externa ao status não só de fornecedora de informações quantitativas, mas também de pedra fundamental para orientar as diversas políticas de melhoria nos resultados da educação.

A LDB/1996 já mencionava que o Plano Nacional de Educação (PNE), com vigência decenal, deveria considerar as diretrizes e metas da Declaração Mundial sobre Educação para Todos. Para a sua discussão e proposição, o MEC e setores organizados da sociedade civil promoveram conferências em nível nacional e regionais em todo o país. Nesta mobilização, especial destaque teve o Fórum Nacional em Defesa da Escola Pública. O texto final do tanto do PNE de 2001/2009, quanto o PNE de 2014/2023 trazem as marcas dos embates ocorridos ao longo dos anos de suas discussões e tramitações, especialmente, quando se tratava do tema da aplicação de recursos para garantir o alcance das metas. Contudo, não restam dúvidas de que os objetivos e metas dos Planos aprovados incorporaram algumas demandas históricas da população brasileira, a despeito das restrições e vetos que sofreram.

Há que se mencionar que o Ministério da Educação do governo Lula lança, em 2007, o Plano de Desenvolvimento da Educação (PDE), instituído pelo Decreto no 6.094, o qual define uma série de diretivas

${ }^{1}$ DECLARAÇÂO MUNDIAL SOBRE EDUCAÇÂO PARA TODOS. Jomtien, Tailândia, 5 a 9 de março de 1990. Disponível em: http://www.unicef.org/brazil/pt/resources_10230.htm 
para as políticas educacionais atuais. Trata-se de uma política pública, um conjunto de metas e ações, associado ao Plano de Aceleração do Crescimento (PAC), o qual envolve diferentes ações da economia para impulsionar o crescimento econômico do país. Demerval Saviani (2009) afirma que o PDE não conflitua com o PNE 2001/2010 vigente na época: este apontava as diretrizes gerais para a educação e aquele estabelece mecanismos concretos de realização. Ele elenca diretrizes programáticas, que se desdobraram no Plano de Metas e Compromissos Todos pela Educação, agrupados em três grandes áreas de atuação: Gestão Educacional, Programa de Formação de Professores e Profissionais de Educação e Infraestrutura e Apoio Educacional.

Saviani (2009) ainda afirma que, ao ascender ao poder, o PT buscou uma aproximação maior com o setor empresarial, distanciando-se de suas bases originárias, o que explica, de certo modo, porque o MEC formulou o PDE com uma interlocução muito maior com o empresariado do que com os movimentos dos educadores que constituíam uma frente histórica mais longa de lutas pela melhoria da educação e das condições de ensino no país. Com isso, o PDE assumiu uma agenda fortemente apoiada e patrocinada por grandes grupos que endossaram o movimento Compromisso Todos Pela Educação, como a Fundação Bradesco, o Grupo Pão de Açúcar, a Fundação Roberto Marinho, o Instituto Gerdau, o Instituto Ayrton Senna, o Banco Santander, a Fundação Itaú-Social, entre outros.

O PDE traz como novidade uma série de instrumentos voltados para o alcance das metas concretas em torno da melhoria da qualidade da educação: O Índice de Desenvolvimento da Educação (IDEB), o Termo de Adesão do Compromisso todos pela Educação, a criação de mecanismo de assistência técnica e financeira da União às unidades escolares públicas e a criação do Plano de Ações Articuladas (PAR). ${ }^{2}$

Em 27 de novembro de 2009, por meio da Portaria ํ⒈129, o Ministério da Educação constituiu a Rede Nacional de Formação Continuada dos Profissionais da Educação Básica com a responsabilidade de definir e coordenar a atuação do MEC na política de formação de professores através de ações articuladas das diversas Secretarias do Ministério da Educação, da CAPES e do FNDE - Fundo Nacional de Desenvolvimento da Educação, atuando também junto aos sistemas públicos de ensino. (CIOFFI e BUENO, 2011)

Em 2010, foi instituído mais um programa: Mais Educação. Instituído pelo Decreto n 7.083 (BRASIL, 2010), o referido programa passa a integrar as ações do Plano de Desenvolvimento da Educação (PDE), como uma estratégia do Governo Federal para induzir a ampliação da jornada escolar e a organização curricular, na perspectiva da Educação Integral. Trata-se da construção de uma ação intersetorial entre as políticas públicas educacionais e sociais, visando a diminuição das desigualdades educacionais e a valorização da diversidade cultural brasileira. Fazem parte os Ministérios da Educação, do Desenvolvimento Social e Combate à Fome, da Ciência e Tecnologia, do Esporte, do Meio Ambiente, da Cultura, da Defesa e a Controladoria Geral da União.

No que se refere ao PNE 2014/2023, longo foi o percurso para que o Congresso Nacional, finalmente, 0 aprovasse e a presidente 0 assinasse em 25 de junho de 2014. Aliás, o Brasil ficou sem um Plano Nacional para a Educação durante quatro anos, visto que o anterior vigeria até 2010. Como dito anteriormente, a demora em sua aprovação se deu principalmente em função do financiamento das metas e estratégias propostas. Ele apresenta dez diretrizes que são as orientações gerais que fundamentam as vinte metas do Plano e cada uma das metas se desdobra em uma série variável de estratégias.

A Meta 6 do PNE vem ampliar e consolidar a política pública na oferta de educação em tempo integral.

\footnotetext{
${ }^{2}$ IDEB é o índice calculado a partir dos dados sobre o rendimento escolar obtido através do Censo Escolar e do Sistema Nacional de Avaliação da Educação Básica (SAEB). Passa a ser indicador objetivo para a verificação do cumprimento das metas no Termo de Adesão do Compromisso todos pela Educação, com as quais os estados e municípios signatários se comprometem, passando a ter acesso aos programas, à assistência técnica e ao financiamento vinculados ao Plano de Ações Articuladas (PAR), elaborados pelos estados e municípios.
} 


\section{Esther Hermes Lück, Neide Lúcia de Oliveira Almeida e Rafael Cuba Mancebo}

Diz a meta: "oferecer educação em tempo integral em, no mínimo $50 \%$ das escolas públicas, de forma a atender, pelo menos, $25 \%$ dos alunos da educação básica".

Tal qual o Decreto $n^{\circ} 7.083 / 2010$, os princípios da Educação Integral no PNE são traduzidos pela compreensão do direito de aprender como inerente ao direito à vida, à saúde, à liberdade, ao respeito, à dignidade e à convivência familiar e comunitária e como condição para o próprio desenvolvimento de uma sociedade republicana e democrática. Por meio da Educação Integral, reconhecem-se as múltiplas dimensões do ser humano e a peculiaridade do desenvolvimento de crianças, adolescentes e jovens.

Logo após a promulgação do PNE, a partir de agosto de 2014, o MEC intensifica o convite às Universidades a oferecerem cursos de extensão, por meio da UAB, para atender demandas de capacitação de professores e agentes que participam da comunidade da escola, em áreas específicas tais como Educação Ambiental, Conselhos Escolares e Educação Integral.

A Universidade Federal Fluminense aceitou o desfio de oferecer cursos nessas áreas e este artigo traz a experiência do planejamento, execução e avaliação e da fundamentação teórico-metodológica do curso de extensão "A escola e a cidade - políticas públicas em educação", voltado para a temática da educação integral em tempo integral.

\section{Curso}

O curso de extensão "A Escola e a Cidade" se insere no programa Mais Educação do Ministério de Educação o qual pretende contribuir com o processo de implementação da política de Educação Integral, assim como contribuir com o Projeto Político-Pedagógico da escola e a reorganização do seu tempo escolar na perspectiva da Educação Integral. Objetiva oferecer formação continuada na modalidade semipresencial para professores, gestores e membros da comunidade que atuam junto às escolas de Educação Básica, com carga horária de 180 horas e uma meta física de 175 cursistas.

A interação entre os professores, tutores e cursistas foi mediada por um Ambiente Virtual de Aprendizagem (AVA), que utiliza a Plataforma Moodle da Coordenação de Educação a Distância (CEAD/UFF). Desta forma, foram disponibilizados textos, apresentações em slides, diagramas, imagens, vídeos e outros recursos audiovisuais. Atividades avaliativas foram propostas, orientadas e corrigidas também por meio do AVA, assim como os recursos para a realização de fóruns e chats, troca de mensagens e de materiais entre os envolvidos nos processos de ensino-aprendizagem foram explorados. Foram realizados cinco encontros presenciais estruturados em torno de atividades interativas e conduzidos por professores e tutores capacitados para o aprofundamento das questões pautadas no curso.

O material didático utilizado foi elaborado pelos professores do STE, acrescido do material sobre 0 programa Mais Educação elaborado pelo MEC para a orientação dos professores.

Além das atividades avaliativas obrigatórias, os cursistas elaboraram um Projeto de Intervenção Pedagógica no contexto da escola, sendo um trabalho individual orientado pelos os tutores. Os trabalhos foram apresentados em formato de banner para avaliação e a cópias impressas e em CD e entregues no prazo fixado no Plano de Atividades.

\section{0 referencial teórico do Curso}

A base teórica da proposta pedagógica do curso em análise articula a formação de professores na perspectiva da educação empreendedora a qual passamos a explicitar.

A formação de professores (inicial, continuada ou em serviço) têm preocupado os gestores da educação, mas os planos que vêm sendo concretizados ainda não produziram os resultados necessários em termos de mudanças na prática docente e na qualidade da educação. Com isso, muitas críticas são feitas à formação recebida pelos professores e a qualidade do trabalho realizado por eles em sala de aula, recaindo sobre os mesmos a responsabilidade pelo baixo desempenho dos alunos nos testes de avaliação da qualidade da educação como o SAEB, Prova Brasil, ENEM, etc. (RICHIT, 2010, p. 182)

A polêmica que se estabeleceu a partir da adoção das políticas voltadas para a melhoria da qualidade da 
educação em geral, sobretudo a aplicação do conceito de accountability ${ }^{3}$ na área educacional, trouxe à tona uma indispensável discussão, principalmente quando se pretende refletir uma visão empreendedora de educação: a profissionalidade docente. Vamos explicitar esse conceito iniciando com o de docência.

A docência é uma profissão e, como tal, procura assegurar à pessoa que a exerce o domínio adequado da ciência (conhecimento) e da técnica (competência profissional). A formação de professores é uma área do conhecimento que se ocupa do estudo dos processos através dos quais os professores aprendem e desenvolvem a sua competência profissional de ensinar.

Nóvoa (1992) conceitua formação de professores como a área de conhecimentos, investigação e de propostas teóricas e práticas, que estuda os processos através dos quais os professores - em formação ou em exercício - se envolvem, individualmente ou em equipe, em experiências de aprendizagem. Afirma, ainda, que por meio delas os professores adquirem ou aprimoram seus conhecimentos, competências e disposições que lhes permitem intervir profissionalmente no desenvolvimento do seu ensino, do currículo e da escola, com o objetivo de melhorar a qualidade da educação. A integração teoria e prática na formação dos professores é reiterada por Nóvoa quando enfatiza que os professores desenvolvem um conhecimento próprio, produto de suas experiências e vivências pessoais e profissionais.

Seguindo essa linha de raciocínio, entendemos que a profissionalidade do professor constitui-se pela autonomia que ele exerce diante de seu trabalho e pela responsabilidade que assume em relação à sua permanente formação, aprendendo e refletindo sobre suas práticas. Podemos depreender disso, então, que 0 "ser professor" vive no desafio permanente da melhoria e na interrogação constante que a sociedade do conhecimento lhe coloca.

É nesta sociedade do conhecimento que nascem novos desafios para a construção de uma profissionalidade docente progressivamente pautada por critérios que de modo algum podem ignorar 0 humano e o profissional. É nesta sociedade que se torna imprescindível que as escolas e os professores tenham uma autonomia ${ }^{4}$ mais profunda, e menos leviana, para agir e decidir diante da crescente necessidade de aumentar as qualificações e o domínio de saberes e de processos de aprender por parte das pessoas. É numa sociedade que demanda força de trabalho qualificada, capaz de atentar para um cenário em que novas qualificações vão sendo exigidas não só para o exercício profissional, mas também para a vida em sociedade.

Bellochio afirma que a profissionalidade do professor depende, entre outros fatores, de como ele mesmo compreende e analisa suas práticas educativas, como articula saberes da docência no seu ato de ensinar, como reflete na ação diante do inesperado e do desconhecido que constituem grande parte de sua atividade. Sobre esse ponto, a autora chama a nossa atenção para o fato de que, diante do inesperado, o professor age fazendo uso de seu reservatório de conhecimentos, impulsionando assim sua autoformação. Com esse movimento, o professor exerce sua "sabedoria prática", a phrónesis ${ }^{5}$ de Aristóteles, a partir de seus valores,

\footnotetext{
${ }^{3}$ Accountability: do inglês que expressa dois conceitos: prestação de contas e responsabilização. Aplicado à escola, a noção prestação de contas significa a cobrança legítima de uma educação pública de qualidade em troca da manutenção da escola com recursos públicos oriundos do impostos pagos pela população. A responsabilização expressa a ideia de que o publico tem o direito de exigir que uma escola assuma a responsabilidade direta pelos resultados de seus alunos. (GAME, 2011, p. 50-51)

${ }^{4}$ Autonomia do professor não pode ser confundida com sua autonomização. Esta se refere ao direito arbitrário de agir despregado de normas que regem a conduta do grupo social ao qual pertence, sem admitir interferência externa, e aquela, associada à ideia de autoridade (ser autor, ou seja, ter capacidade de produção própria), se refere à dimensões pessoais e profissionais que permitem ao professor se apropriar dos seus processos de formação para atribuir-lhe sentido em sua vida: ser ao mesmo tempo autor e autônomo.

${ }^{5}$ Aristóteles nos ensina com sua phrónesis que a sabedoria prática do professor resulta de sua capacidade de agir de modo correto nas situações de ensino com fundamento nos conhecimentos de sua área e na experiência pedagógica. Ele entendia a sabedoria prática como uma combinação do conhecimento e da experiência com a capacidade interpretar de maneira correta as situações. Quando se pensa em tomar uma decisão correta, entramos no território da
} 


\section{Esther Hermes Lück, Neide Lúcia de Oliveira Almeida e Rafael Cuba Mancebo}

seus princípios e suas convicções éticas e políticas.

O conhecimento do conteúdo a ser ensinado é condição necessária, porém não é suficiente para garantir a aprendizagem dos alunos.

A importância dada a este tipo de conhecimento deve-se ao fato de não ser um conhecimento que possa ser adquirido de forma mecânica ou linear; nem sequer pode ser ensinado nas instituições de formação de professores, uma vez que representa uma elaboração pessoal do professor ao confrontar-se com o processo de transformar em ensino o conteúdo aprendido ao longo de sua vida e carreira.

Quando criamos este curso de extensão, buscamos associar os referenciais teóricos da profissionalidade docente com os da educação empreendedora. Partimos do pressuposto de que o caminho profissional do professor se faz ao caminhar, ou seja, se faz num contínuo, marcado pela capacidade de renovação e de luta contra a rotina, pelo entusiasmo em abraçar a atividade de ensinar como um processo de aprendizagem em permanente construção marcado por um pensamento estratégico, por um comportamento autorregulado e pela identificação de oportunidades e recursos que faz dele um protagonista, um empreendedor de sua formação.

Ao ser o empreendedor de sua formação profissional, o professor prima pela competência em ensinar, ou seja, domina cada vez mais as estratégias de ensino no seu campo de conhecimento e tem a plena consciência de que a profissionalidade docente é algo que se relaciona intimamente à qualidade dos processos de aprendizagem dos alunos.

A seguir, apresentamos alguns dados obtidos resultantes da avaliação que os alunos fizeram do curso.

\section{Principais Resultados do Curso}

Alinhado ao processo teórico metodológico do curso, o processo de avaliação do curso pelos professores-cursistas foi uma etapa fundamental que permitiu a equipe de gestão acompanhar 0 andamento do curso, como também, identificar pontos de melhoria. Foram avaliados aspectos como conteúdo, equipe de coordenação e tutores e autoavaliação.

O perfil dos cursistas foi majoritariamente feminino, sendo 93\% mulheres e $7 \%$ homens.

Com as atividades do curso realizadas no Ambiente Virtual de Aprendizagem (AVA) Moodle, a frequência de acesso à plataforma também foi mapeada, permitindo que se acompanhasse a relação entre 0 acesso e 0 desempenho dos cursistas nas disciplinas. Dessa forma, $68 \%$ dos respondentes afirmaram acessar a plataforma de 3 a 4 vezes por semana.

\section{Frequência de acesso à plataforma}

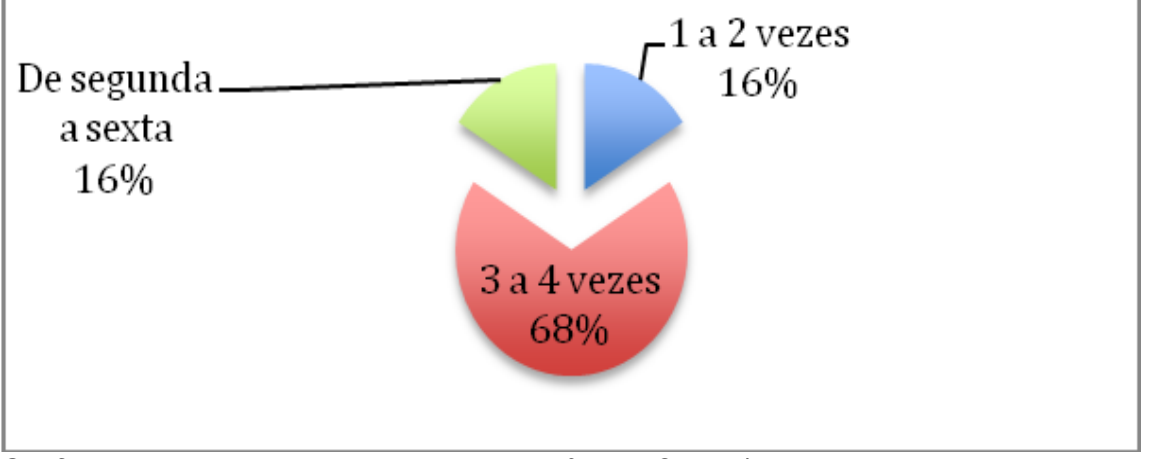

Gráfico 1: Frequência de acesso à plataforma CEAD/UFF.

Fonte: Elaboração própria.

ética, o que pressupõe os fins últimos, isto é, o bem do homem. Ele dava ênfase ao cultivo do caráter e do hábito de atuar de maneira sábia. Deste modo, podemos inferir que é através de um saber-fazer reflexivo que o professor fortalece os seus valores éticos, emancipadores e democráticos, fortalecendo também sua profissionalidade. 
Já os encontros presenciais, realizados mensalmente aos sábados, foram avaliados como relevantes para $100 \%$ dos cursistas. Os encontros eram momentos para apresentação e revisão de conteúdos, assim como para contato presencial com os tutores.

Além disso, a avaliação permitiu que a equipe de gestão do curso conhecesse os maiores desafios para que os cursistas concluíssem o curso. Nesse sentido, $46 \%$ dos respondentes tiveram como maior dificuldade o "tempo de dedicação ao curso", muitas vezes como resultado das grandes jornadas de trabalho que os profissionais da área de educação enfrentam no dia a dia da escola e que pode ter impactado, também, nos $86 \%$ dos cursistas que acharam o conteúdo do curso mais profundo do que esperavam.

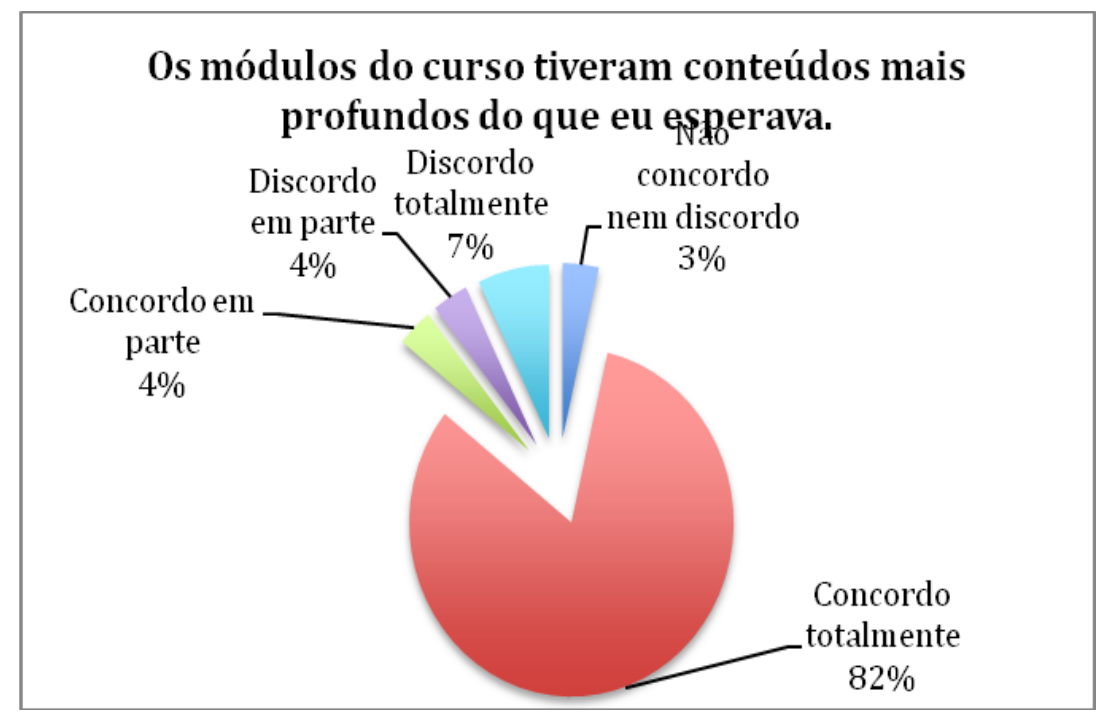

\section{A(s) minha (s) principal (ais) dificuldade (s) para concluir o curso foi:}

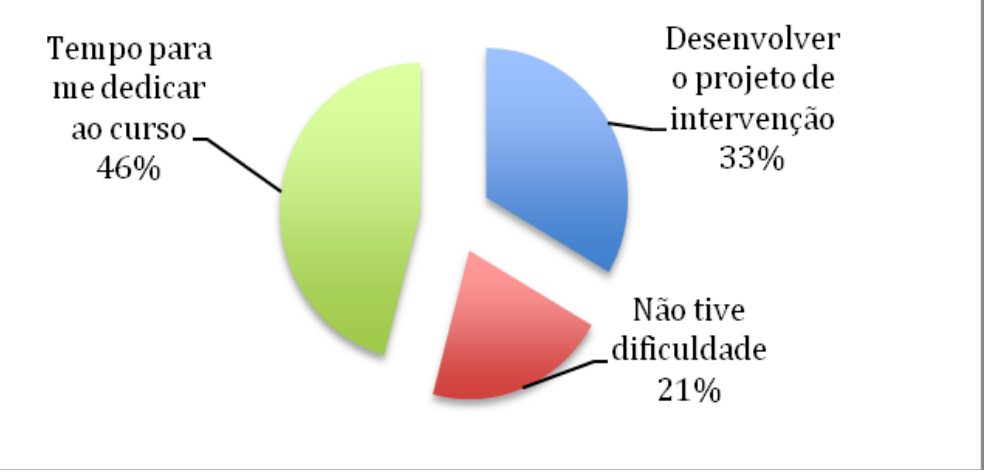

Gráfico 2 e 3: Dificuldade encontrada pelos cursistas.

Fonte: Elaboração própria.

Por fim, a avaliação geral do curso permitiu analisar a relevância do conteúdo e da proposta pedagógica, mostrando que para $96 \%$ dos cursistas o curso foi relevante para a sua formação e que o recomendariam. 


\section{Esther Hermes Lück, Neide Lúcia de Oliveira Almeida e Rafael Cuba Mancebo}

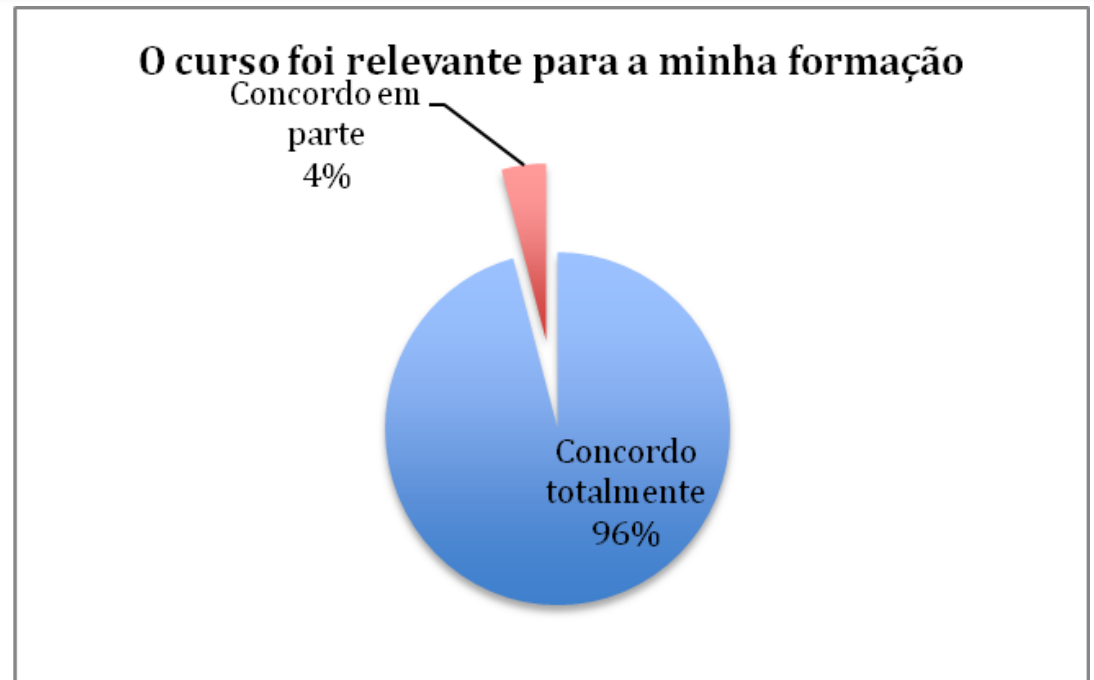

Figura 4: Relevância do curso para a formação dos cursistas

Fonte: Elaboração própria.

\section{Considerações Finais}

O curso de extensão "A Escola e a Cidade", oferecido pelo Departamento de Empreendedorismo e Gestão da Universidade Federal Fluminense, cumpriu o seu objetivo primordial que foi o de contribuir com 0 processo de implementação da política de Educação Integral e contribuir com o Projeto Político-Pedagógico das escolas e com a reorganização do seu tempo escolar na perspectiva da Educação Integral.

Dos cursistas que obtiveram aprovação nos módulos estudados, aptos a apresentarem seus Projetos de Intervenção ao final do curso, pode-se verificar que a ideia da integração da Escola-Cidade e a da Cidade como o "quintal da Escola" foram assimiladas com sucesso, conforme princípio teórico apresentado, cujas atividades de produção individual sugeriram à exaustão.

Espera-se que o curso de extensão "A Escola e a Cidade" e os Projetos de Intervenção apresentados nesta Edição sirvam de inspiração a profissionais ávidos por intraempreender em suas instituições. Mais ainda, que despertem nesses a curiosidade e o desejo de integrarem as novas turmas do curso de extensão, não apenas movidos pelo desejo de aumentar a sua profissionalidade mas, principalmente, pela determinação de se capacitarem para oferecer mais e melhor Educação às suas comunidades.

\section{Referências}

BELLOCHIO, Cláudia Ribeiro et al. Profissão docente: algumas dimensões e tendências. Educação. Santa Maria: UFSM, v.19, no. 2, 2004. Disponível em: http://coralx.ufsm.br/revce/revce/2004/02/ a2.htm

BRASIL. Leis e Decretos. Decreto no. 6755, de 29/01/2009. Institui a Política Nacional de Formação de Profissionais do Magistério da Educação Básica, disciplina a atuação da Coordenação de Aperfeiçoamento de Pessoal de Nível Superior -CAPES no fomento a programas de formação inicial e continuada, e dá outras providências. Disponível em: http://www.planalto.gov.br/ccivil_03/_ato2007-2010/2009/decreto/d6755.htm

Decreto No. 7083, de 27 de janeiro de 2010. Dispõe sobre o programa Mais Educação. Disponível em: http://www.planalto.gov.br/ccivil_03/_ato2007-2010/2010/decreto/d7083.htm

. Lei no 9394 de 20 de dezembro de 1996. Estabelece as diretrizes e bases para a educação nacional. Disponível em:

https://www.planalto.gov.br/ccivil_03/Leis/L9394.htm 
CIOFFI, Lara Cristina e BUENO, José Lucas P. Análise das bases legais que fundamentam a política de formação de professores no Brasil. Simpósio ANPAE, 25. São Paulo, 26 a 30 de abril de 2011. Disponível em: http://www.anpae.org.br/simposio2011/cdrom2011/PDFs/trabalhosCompletos/comunicacoesRelatos/0278.pdf

DIAS-DA-SILVA, Maria Helena Galvão Frem. O professor e seu desenvolvimento profissional: superando a concepção do algoz incompetente. Cad. CEDES, Campinas, vol.19, n.44, p. 33-45, 1998. Disponível em: http://www.scielo.br/scielo.php?script=sci_arttext\&pid=S0101-32621998000100004\&lng=en\&nrm=iso

LÜCK, Esther Hermes; PINHO, Fernando. A voz dos professores: contribuições para projetos de formação inicial e continuada de professores. Seminário Estadual da ANPAE-RJ, 4. Niterói, 24 a 26 abril de 2014. 18p. NÓVOA, António (org) . Os professores e a sua formação. Lisboa: Dom Quixote, 1992. p. 13-33. Disponível em:

http://repositorio.ul.pt/handle/10451/4758

RIGHIT, Adriana. Avaliação da educação e formação continuada docente: horizontes e contradições nas políticas públicas. RBPEA, v.26, n.1, p. 173-193, jan./abr. 2010.

SAVIANI, DEMERVAL. Plano de Desenvolvimento da Educação: análise crítica da política do MEC. Campinas: Autores Associados, 2009. (Políticas de Nosso Tempo, 99) 